\title{
Sex-related differences in COPD in five Latin American cities: the PLATINO study
}

\author{
M.V. Lopez Varela*, M. Montes de Oca\#, R.J. Halbert ', A. Muiño*, R. Perez-Padilla+, \\ C. Tálamo ${ }^{\#}$, J.R.B. Jardim ${ }^{\S}$, G. Valdivia ${ }^{\prime}$, J. Pertuzéf ${ }^{f}$, D. Moreno ${ }^{\#}$ and \\ A.M.B. Menezes** for the PLATINO Team
}

ABSTRACT: There is evidence to suggest sex differences exists in chronic obstructive pulmonary disease (COPD) clinical expression. We investigated sex differences in health status perception, dyspnoea and physical activity, and factors that explain these differences using an epidemiological sample of subjects with and without COPD.

PLATINO is a cross-sectional, population-based study. We defined COPD as post-bronchodilator forced expiratory volume in $1 \mathrm{~s} /$ forced vital capacity ratio $<0.70$, and evaluated health status perception (Short Form (SF)-12 questionnaire) and dyspnoea (Medical Research Council scale).

Among 5,314 subjects, 759 (362 females) had COPD and 4,555 (2,850 females) did not. In general, females reported more dyspnoea and physical limitation than males. $54 \%$ of females without COPD reported a dyspnoea score $\geqslant 2$ versus $35 \%$ of males. A similar trend was observed in females with COPD (63\% versus $44 \%)$. In the entire study population, female sex was a factor explaining dyspnoea (OR $1.60,95 \% \mathrm{Cl} 1.40-1.84)$ and SF-12 physical score $(\mathrm{OR}-1.13,95 \% \mathrm{Cl}$ $-1.56--0.71$ ). $40 \%$ of females versus $28 \%$ of males without COPD reported their general health status as fair-to-poor. Females with COPD showed a similar trend ( $41 \%$ versus $34 \%)$. Distribution of COPD severity was similar between sexes, but currently smoking females had more severe COPD than currently smoking males.

There are important sex differences in the impact that COPD has on the perception of dyspnoea, health status and physical activity limitation.

KEYWORDS: Chronic pulmonary disease, epidemiology, health status, sex, susceptibility

hronic obstructive pulmonary disease (COPD) is a leading cause of death and chronic morbidity with increasing worldwide prevalence [1-6].

Although COPD has historically been more common in males, there are data suggesting that females may be at increased risk of developing COPD, as females seem to be more susceptible to the toxic effects of tobacco smoke than males [79]. It has been hypothesised that sex differences in smoking effects could be the result of factors such as sex-related differences in airway geometry, smoking behaviour, respiratory symptoms and environmental or occupational exposures.

Early studies suggested that females have more severe disease and greater COPD-associated mortality for the same degree of tobacco exposure [10], whereas a recent study showed that allcause and respiratory mortality are significantly lower in females than in males with similar
COPD severity [11]. A recent analysis of the Framingham offspring cohort also found higher mortality in males with COPD [12]

There is increasing evidence in selected COPD populations supporting sex differences in the clinical expression of COPD. Female patients report more anxiety and depression, worse symptoms, have lower exercise capacity, more airway hyperresponsiveness and perceive a worse healthrelated quality of life (HRQoL) [13-18]. These data suggest that the manifestations of COPD may differ in females; thus, the influence of sex on the expression of COPD is now receiving increased attention.

To our knowledge there is no information available regarding sex differences in the clinical expression of COPD from an unselected population-based sample. The Proyecto Latinoamericano de Investigación en Obstrucción Pulmonar (PLATINO) study offers an opportunity to explore sex differences in a large,
AFFILIATIONS

*Universidad de la República,

Facultad de Medicina, Montevideo, Uruguay.

\#Universidad Central de Venezuela, Facultad de Medicina, Caracas, Venezuela.

"UCLA School of Public Health, Los Angeles, CA, USA.

+Institute of Respiratory Diseases, Mexico City, Mexico.

${ }^{\S}$ Federal University of São Paulo, São

Paulo, and

**Post-graduate Program in

Epidemiology, Federal University of

Pelotas, Pelotas, Brazil.

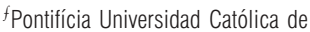

Chile, Santiago de Chile, Chile.

${ }^{f f} \mathrm{~A}$ list of the other members of the PLATINO Team and their affiliations

can be found in the

Acknowledgements section.

\section{CORRESPONDENCE}

M.V. Lopez Varela

Cátedra de Neumología, Facultad de Medicina, Universidad de la

República

Hospital Maciel

Montevideo

Uruguay

E-mail: victorina.lopezvarela@

gmail.com

Received:

Oct 182009

Accepted after revision:

March 262010

First published online:

April 082010 
multicentre, population-based sample that includes persons with and without COPD from five Latin American cities with high participation and robust, well-established methods [2,19]. The aims of this study were, therefore: 1 ) to explore differences by sex and COPD status in subjects' perception of general health status, degree of breathlessness and physical activity limitation; 2) to evaluate sex differences in airway obstruction in the population with COPD; and 3) to explore the possible factors explaining dyspnoea and health status in the entire study population.

\section{PATIENTS AND METHODS}

Details of the selection method and population sample size of PLATINO have been published previously [19]. Multistage cluster sampling was used to obtain a representative sample of subjects $\geqslant 40$ yrs of age from the metropolitan area of five large Latin American cities. The study protocol was approved by the ethical committee of each site and the participants gave signed, informed consent.

Participants completed a questionnaire to collect information on factors potentially associated with COPD including: demographics; smoking habits; education; employment; respiratory symptoms; use of respiratory medication; and prior spirometric testing. Data on prior medical diagnosis of tuberculosis, asthma, chronic bronchitis, emphysema, COPD, self-reported exacerbations and hospitalisations were also obtained. A simple comorbidity score was calculated by counting the number of comorbid conditions (heart disease, hypertension, stroke, diabetes, ulcer and asthma) reported by each subject. Study questionnaires are available on the internet (www.platino-alat.org).

Spirometry was performed using the portable, battery-operated ultrasound Easy One spirometer (ndd Medical Technologies, Zurich, Switzerland). Spirometry tests were performed at baseline and $15 \mathrm{~min}$ after the administration of $200 \mu \mathrm{g}$ salbutamol, according to the American Thoracic Society criteria of acceptability and reproducibility. Acute bronchodilator responsiveness was defined using the following criteria: forced vital capacity (FVC) and/or forced expiratory volume in $1 \mathrm{~s}$ (FEV1) $\geqslant 12 \%$ plus $\geqslant 200 \mathrm{~mL}$ improvement [20]. We used the definition and severity stratification of COPD proposed by the Global Initiative for Chronic Obstructive Lung Disease (GOLD): a ratio of the post-bronchodilator (BD) FEV1/FVC $<0.70$ [1]. In addition, we also performed a sensitivity analysis using the lower limit of normal (LLN) using equations derived from the National Health and Nutrition Examination Survey (NHANES) III for post-BD FEV1/FVC because of the potential for differential misclassification between sexes. Notably, 137 subjects (94 females and 43 males) were missing data on LLN.

Health status was assessed using the Short Form (SF)-12 generic quality of life questionnaire. Patients' perception of their general health status was derived from the question "in general you would say that your health is: excellent, very good, good, regular or poor". Information regarding physical activity limitation due to state of health was assessed using the SF-12 physical score: a detailed description of the questions used has been published previously [21]. The degree of breathlessness was assessed using the Medical Research Council (MRC) dyspnoea scale, from grade 1 (no dyspnoea) to grade 5 (maximum dyspnoea, detailed information has been published previously) [21]. For this study, COPD exacerbations were selfreported and defined by deterioration of breathing symptoms that affected usual daily activities or caused missed work. The questions used for assessing self-reported COPD exacerbation have been published previously [22].

\section{Statistical analysis}

Descriptive analyses included group comparisons using Pearson's Chi-squared test (adjusted for survey design) for nominal variables, the Mann-Whitney test and ordered logistic regression (adjusted for survey design) for ordinal variables, and the Wald test (adjusted for survey design) for continuous variables. Linear and logistic regression models (adjusted for survey design) were used to evaluate multivariable relationships. The STATA software package version 10.1 (Stata Corporation, College Station, TX, USA) was used for all analyses.

\section{RESULTS}

From a total of 6,711 eligible subjects at all sites, 5,571 individuals completed questionnaires and 5,314 spirometry tests were performed. Among this population, 759 subjects had a post-BD FEV1/FVC $<0.70$ (COPD), and 4,555 individuals were not obstructed (post-BD FEV1/FVC $\geqslant 0.70$ ) (fig. 1). Significant regional differences in sex distribution were observed in subjects without COPD but not in those with COPD (Supplemental table 1).

A description of subjects by sex and COPD status is presented in table 1. Among subjects with COPD, 362 (47.7\%) were female; in subjects without COPD, 2,850 (62.6\%) were female. Compared to persons without COPD, both females and males with COPD were more likely to be older, unemployed, have a lower education level and body mass index (BMI), and have higher smoking exposure, more respiratory symptoms, more comorbidity, more use of respiratory medication, and were more likely to report a prior diagnosis of tuberculosis and prior spirometry test. Females with COPD were more likely to be white than were females without COPD. Comparing sexes among subjects with COPD, females smoked less than males,

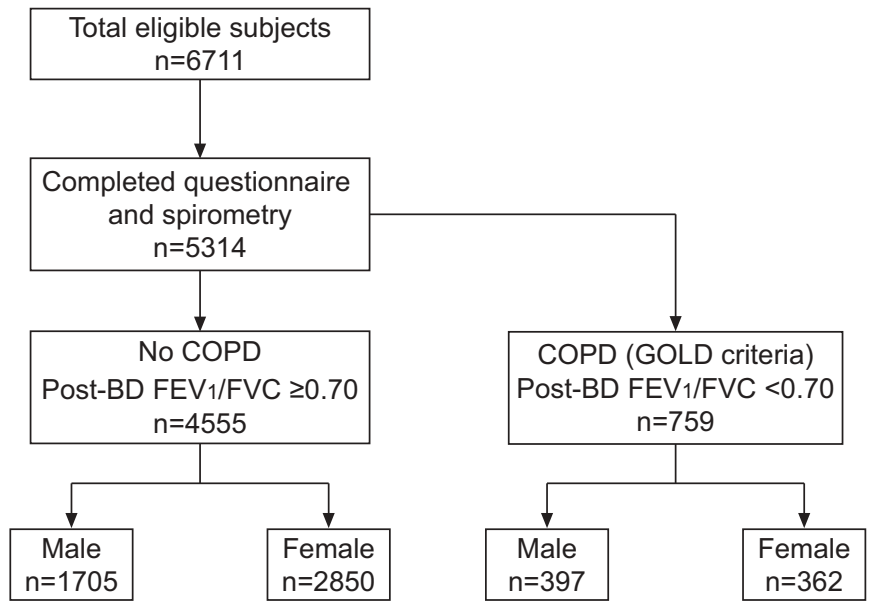

FIGURE 1. Flow-chart showing study participants by sex and chronic obstructive pulmonary disease (COPD) condition. Post-BD: post-bronchodilator; FEV1: forced expiratory volume in 1 s; FVC: forced vital capacity; GOLD: Global Initiative for Chronic Obstructive Lung Disease. 
were less likely to be current smokers, had higher BMI and were more likely to report dyspnoea, use of respiratory medicine and comorbidity. Comparing sexes among subjects without COPD, females were more likely to be older, white, unemployed, had less smoking exposure (pack-yrs) and education level, had higher BMI, more respiratory symptoms (in particular dyspnoea), more comorbidity and were more likely to report use of respiratory medication than males with COPD.

Using the LLN criterion to define COPD, there was an increase in the proportion of females among subjects with COPD from $51.5 \%$ (95\% CI 47.4-55.6) using LLN versus $47.7 \%$ (95\% CI $44.2-$ 51.2) with fixed ratio. For the relationship between descriptive variables, sex and COPD status, results were generally similar between the two definitions (Supplemental table 2).

Figure 2 shows dyspnoea severity distribution by sex and COPD status. For both sexes, persons with COPD reported significantly more dyspnoea than those without. Within strata defined by COPD status, females reported significantly more dyspnoea than males. Similar results were observed using the LLN criterion to define chronic obstructive pulmonary disease (data not presented).

Table 2 shows health status (SF-12) data. Compared to persons without COPD of the same sex, both females and males with COPD were more likely to have a lower SF-12 physical score and report limitation in physical activities and at work. The SF12 mental score in females with COPD was higher than in females without COPD, whereas no such difference was observed in males. Leisure impairment was more likely in males with COPD than in males without COPD. Among persons with COPD, females were more limited in physical activities, had more work limitation, and had lower SF-12 mental and physical scores than males. Among subjects without COPD, females also reported more physical activity limitation, had lower SF-12 physical and mental scores and more work and leisure limitation than males without COPD. Similar results were observed using the LLN criterion to define COPD (Supplemental table 3).

TABLE 1 Description of subjects by sex and chronic obstructive pulmonary disease (COPD) status

\begin{tabular}{|c|c|c|c|c|}
\hline \multirow[t]{2}{*}{ Variables } & \multicolumn{2}{|c|}{ Female } & \multicolumn{2}{|c|}{ Male } \\
\hline & COPD & No COPD & COPD & No COPD \\
\hline Subjects & 362 & 2850 & 397 & 1705 \\
\hline Age yrs & $64.8 \pm 0.7^{\#}$ & $55.4 \pm 0.2^{\pi}$ & $63.5 \pm 0.6^{\#}$ & $54.3 \pm 0.3$ \\
\hline$B M I \mathbf{k g} \cdot \mathrm{m}^{-2}$ & $27.2 \pm 0.3^{\# \cdot \bullet}$ & $28.8 \pm 0.1^{++}$ & $26.5 \pm 0.2^{+}$ & $27.4 \pm 0.1$ \\
\hline Normal & $100(27.6)$ & $693(24.3)$ & $130(32.8)$ & $423(24.8)$ \\
\hline Overweight & 135 (37.3) & $1066(37.4)$ & $168(42.3)$ & 807 (47.3) \\
\hline Obese & $98(27.1)$ & $1012(35.5)$ & $77(19.4)$ & 419 (24.6) \\
\hline White subjects & $236(65.2)^{+}$ & $1526(53.8)^{\S \S}$ & $253(63.7)$ & $863(50.8)$ \\
\hline Education yrs & $6.5 \pm 0.3^{+}$ & $7.5 \pm 0.1^{++}$ & $6.8 \pm 0.3^{\#}$ & $8.1 \pm 0.2$ \\
\hline Employed & $112(30.9)^{\#, 5}$ & $1303(45.7)^{++}$ & $205(51.6)^{\#}$ & $1299(76.2)$ \\
\hline \multicolumn{5}{|l|}{ Smoking status } \\
\hline Former & $75(20.7)$ & $603(21.2)$ & $172(43.3)$ & $617(36.3)$ \\
\hline Never & $174(48.1)$ & $1541(54.1)$ & $65(16.4)$ & $481(28.3)$ \\
\hline Cough & $118(32.6)^{\#}$ & $582(20.4)^{\S \S}$ & $120(30.2)^{\#}$ & $288(16.9)$ \\
\hline Phlegm & $97(26.8)^{\#}$ & $471(16.5)$ & $118(29.7)^{\#}$ & $308(18,1)$ \\
\hline Wheezing & $142(39.2)^{\#}$ & $620(21.8)$ & $153(38.5)^{\#}$ & $353(20.7)$ \\
\hline Dyspnoea & $214(60.5)^{\# \#, \S}$ & $1469(52.0)^{++}$ & $165(41.9)^{\# \#}$ & 561 (33.3) \\
\hline Self-reported tuberculosis & $19(5.3)^{+}$ & $66(2.3)^{\S 5}$ & $20(5.0)^{\#}$ & $22(1.3)$ \\
\hline Comorbidity score & $1.35 \pm 0.05^{\#, 5}$ & $1.10 \pm 0.02^{++}$ & $1.01 \pm 0.05^{+}$ & $0.79 \pm 0.02$ \\
\hline Any respiratory medication & $69(19.1)^{\#, 9}$ & $172(6.0)^{++}$ & $44(11.1)^{\#}$ & 55 (3.2) \\
\hline Any bronchodilator & $64(17.7)^{\#, 9}$ & $158(5.5)^{++}$ & $43(10.8)^{\#}$ & $47(2.8)$ \\
\hline Any corticosteroid & $25(6.9)^{\#}$ & $45(1.6)^{\S \S}$ & $17(4.3)^{\#}$ & $15(0.9)$ \\
\hline Prior spirometry & $68(18.8)^{\#}$ & $239(8.4)^{++}$ & $84(21.2)^{\#}$ & $212(12.5)$ \\
\hline
\end{tabular}

Data are presented as $n$, mean \pm SE and $n(\%)$. Statistical tests used were as follows: for nominal variables, Pearson Chi-squared adjusted for survey design; for ordinal variables, Mann-Whitney test and ordered logistic regression adjusted for survey design ( $p$-values reflect Mann-Whitney test); for continuous variables, Wald test adjusted for survey design. BMl: body mass index. ${ }^{*}: p<0.0001$ (COPD versus no COPD); ${ }^{\bullet}: p<0.05$ (COPD female versus COPD male); ${ }^{+}$: $p<0.001$ (COPD versus no COPD); ${ }^{s}: p<0.001$ (COPD female versus COPD male); ${ }^{f}: p<0.05$ (COPD versus no COPD); ${ }^{\# \#}: p<0.01$ (COPD versus no COPD); ${ }^{*}:$ p $<0.001$ (no COPD female versus no COPD male); ${ }^{+t}: p<0.0001$ (no COPD female versus no COPD male); ${ }^{\S \S}$ : $p<0.05$ (no COPD female versus no COPD male). 


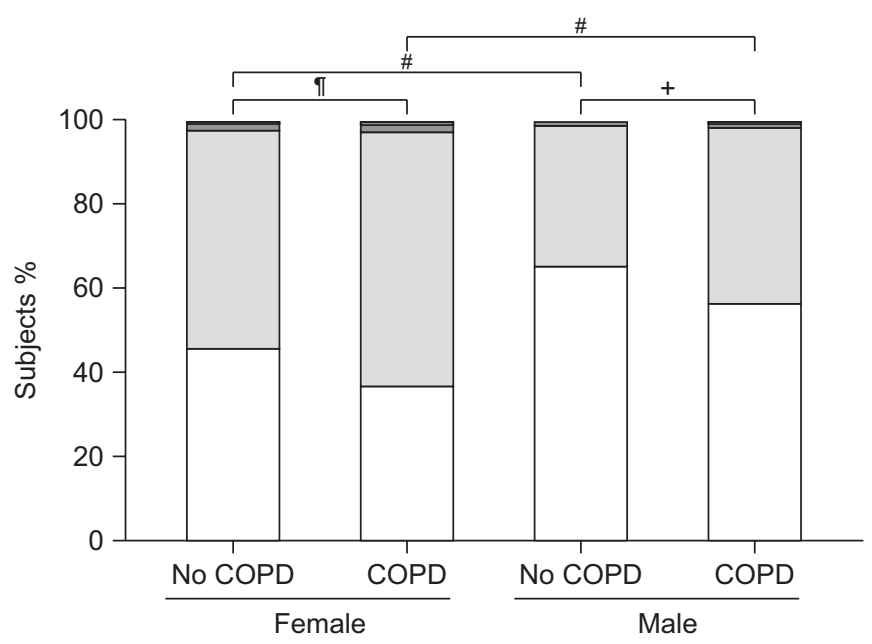

FIGURE 2. Medical Research Council (MRC) dyspnoea by sex and COPD status. Statistical tests: Mann-Whitney test and ordered logistic regression (adjusted for survey design). p-values reflect Mann-Whitney test. $\square$ : MRC 1 ; ㅍ: MRC 2; $\mathbf{\square}:$ MRC 3; $\mathbf{\square}:$ MRC 4 and $5 .{ }^{*}: p<0.0001 ; "$ : $p=0.0015 ;^{+}: p=0.009$.

General health status assessed using the SF-12 questionnaire by sex and COPD status is shown in figure 3 . Females with and without COPD had a similar distribution of general health status categories, whereas males with COPD reported significantly worse general health status than males without COPD. Comparing subjects without COPD, a larger proportion of females $(40 \%)$ than males $(28 \%)$ reported their general health status as fair to poor $(\mathrm{p}<0.0001)$. No such difference was found in subjects with COPD. Similar results were observed using the LLN criterion to define COPD (data not presented).

Among subjects with COPD, $10.2 \%$ of females and $5.8 \%$ of males reported ever having had an exacerbation $(\mathrm{p}<0.05)$. Although there was a trend for females to have more exacerbations, exacerbation-related hospitalisations and exacerbation-related hospital days within the past year, these differences did not achieve statistical significance $(\mathrm{p}>0.05)$ (Supplemental table 4).

Lung function parameters by COPD status and sex are shown in table 3. There were no significant sex differences in pre- or post-BD FEV1 regardless of COPD status. In persons without COPD, post-BD FEV1 change (in $\mathrm{mL}$ ) was significantly larger in males than in females. Pre-BD FVC (\% predicted) was lower in females compared to males with COPD, whereas post-BD FVC (\% pred) was similar in both sexes. Compared to males, females without COPD showed higher pre- and post-BD FVC and FEV1/FVC ratio, although these differences were small. FVC change post-BD was greater in females than males with COPD. Pre-BD FEV1/FVC was higher in females compared to males with COPD. Acute bronchodilator reversibility was more common in females than in males, regardless of COPD status. Similar results were found using the LLN criterion to define COPD (Supplemental table 5).

GOLD severity distribution of COPD subjects by sex and smoking status is shown in figure 4 . Only current smokers showed significant sex differences in COPD severity stratification: over half $(53 \%)$ of females were stage 2 or higher, compared with $35 \%$ of males $(\mathrm{p}<0.01)$. An analysis of smoking exposure showed no significant difference in smoking

TABLE 2 Health status (Short Form (SF)-12) in subjects by sex and chronic obstructive pulmonary disease (COPD) status

\begin{tabular}{|c|c|c|c|c|}
\hline Variables & \multicolumn{2}{|c|}{ Female } & \multicolumn{2}{|c|}{ Male } \\
\hline SF-12 physical subscale & $47.4 \pm 0.52^{\#, 9}$ & $49.9 \pm 0.18^{\# \#}$ & $50.2 \pm 0.44^{\#}$ & $52.6 \pm 0.17$ \\
\hline SF-12 mental subscale & $49.0 \pm 0.59^{\circ}$ & $48.8 \pm 0.22^{\# \#}$ & $52.3 \pm 0.51$ & $52.7 \pm 0.22$ \\
\hline \multicolumn{5}{|l|}{ Limitation } \\
\hline \multicolumn{5}{|l|}{ Moderate activities } \\
\hline Limited a lot & $54(14.9)^{\#, 9}$ & $186(6.5)^{\# \#}$ & $24(6.1)^{\#}$ & $46(2.7)$ \\
\hline Limited a little & 70 (19.3) & $492(17.3)$ & $50(12.6)$ & $118(6.9)$ \\
\hline Not limited at all & $238(65.8)$ & $2172(76.2)$ & $323(81.4)$ & $1540(90.4)$ \\
\hline \multicolumn{5}{|l|}{ Climbing stairs } \\
\hline Limited a lot & $76(21.0)^{\#, 9}$ & $292(10.3)^{\# \#}$ & $34(8.6)^{\#}$ & $51(3.0)$ \\
\hline Limited a little & $96(26.5)$ & $684(24.0)$ & $74(18.6)$ & $204(12.0)$ \\
\hline
\end{tabular}

Data are presented as $n$, mean \pm SE or $n(\%)$. Statistical tests used were as follows: for nominal variables, Pearson Chi-squared adjusted for survey design; for ordinal variables, Mann-Whitney test and ordered logistic regression adjusted for survey design ( $p$-values reflect Mann-Whitney test); for continuous variables, Wald test adjusted for survey design. ${ }^{*}: \mathrm{p}<0.0001$ (COPD versus no COPD); ${ }^{\imath}: \mathrm{p}<0.001$ (COPD female versus COPD male); ${ }^{+}: \mathrm{p}<0.001$ (COPD versus no COPD); ${ }^{\varsigma}: \mathrm{p}<0.01$ (COPD versus no COPD); ${ }^{f}: p<0.05$ (COPD female versus COPD male); ${ }^{\# \#: ~} p<0.0001$ (no COPD female versus no COPD male); ${ }^{\text {" }}: p<0.05$ (COPD versus no COPD) 


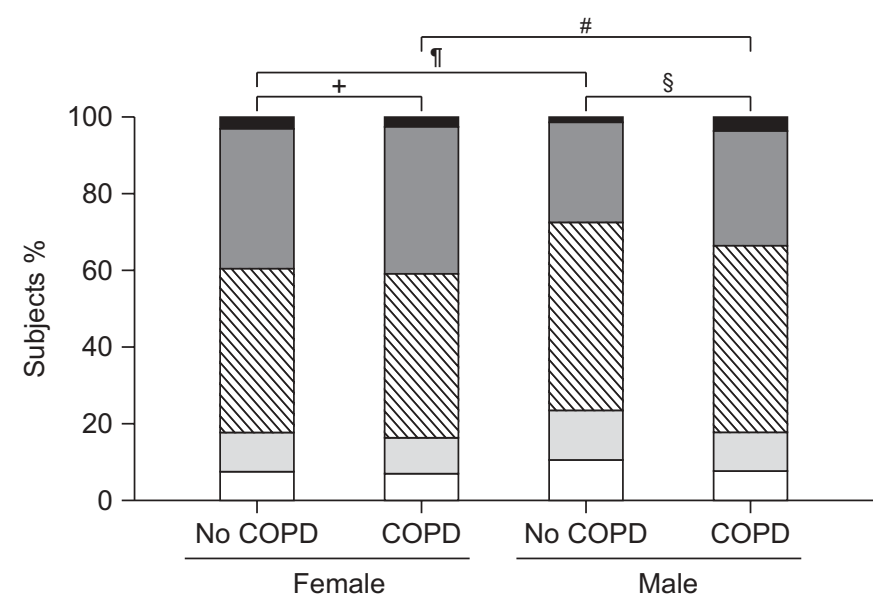

FIGURE 3. Short Form-12 health status by sex and chronic obstructive pulmonary disease (COPD). Statistical tests: Mann-Whitney test and ordered logistic regression (adjusted for survey design). p-values reflect Mann-Whitney test.

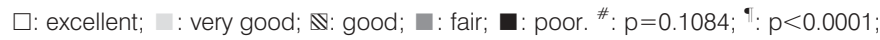
$+: p=0.5307 ;{ }^{\varsigma}: p=0.0016$.

exposure between male and female current smokers. No sex differences in severity were seen among ex-smokers or neversmokers, despite a significant difference in smoking exposure among former smokers.

A multivariable logistic regression model using the entire study population indicated that the presence of dyspnoea was independently associated with female sex, more comorbidity, higher BMI, the presence of wheeze, phlegm and cough, nonwhite race, and having lower FEV1, age, education level, and SF-12 physical and mental scores (table 4). A multivariable linear regression model, again using the entire study population, showed that a higher SF-12 physical score was independently associated with male sex, fewer respiratory symptoms (in particular dyspnoea), less comorbidity, lower age, more education, employment in the past yr, and white race (table 5). Interaction terms did not add significantly to either model.

\section{DISCUSSION}

This study documents important sex differences in the expression of COPD in a population-based sample. First, females reported more dyspnoea and physical limitation than males, independent of COPD status, and female sex was a major factor explaining dyspnoea and physical activity limitation in the entire study population. Secondly, females reported similar general health status regardless of COPD, whereas male subjects with COPD reported worse general health status than those without COPD. In subjects without COPD, females reported worse general health status than males, but in those with COPD no sex difference was observed. Finally, actively smoking females with COPD had more severe obstruction than males, despite similar cigarette exposure.

Some sex differences have been reported in selected COPD populations. In general females with COPD report worse symptoms (in particular dyspnoea), have lower exercise capacity, worse HRQoL, and more anxiety and depression $[13-16,18]$. However, there is general population information from the USA (National Health Interview Survey) and Europe (health status indicators from the Statistics on Income and Living Conditions Surveys) indicating that, compared with males, females report worse health status, more difficulties in physical functioning and more feelings of sadness, hopelessness, worthlessness, nervousness and restlessness [23, 24].

In our study, females reported worse health status perception, more severe dyspnoea and more physical limitation,

TABLE 3 Lung function parameters in subjects with and without chronic obstructive pulmonary disease (COPD) by sex

\begin{tabular}{|c|c|c|c|c|}
\hline \multirow[t]{2}{*}{ Variables } & \multicolumn{2}{|c|}{ Female } & \multicolumn{2}{|c|}{ Male } \\
\hline & COPD & No COPD & COPD & No COPD \\
\hline Subjects & 362 & 2850 & 397 & 1705 \\
\hline \multicolumn{5}{|l|}{ Pre-BD values } \\
\hline FEV $1 \%$ pred & $79.2 \pm 1.4$ & $98.4 \pm 0.4$ & $79.4 \pm 1.2$ & $98.3 \pm 0.4$ \\
\hline \multicolumn{5}{|l|}{ Post-BD values } \\
\hline FEV1 \% pred & $83.3 \pm 1.2$ & $101.8 \pm 0.4$ & $83.6 \pm 1.1$ & $101.2 \pm 0.1$ \\
\hline FVC \% pred & $102.5 \pm 1.2$ & $99.8 \pm 0.3^{*}$ & $103.4 \pm 1.0$ & $98.7 \pm 0.4$ \\
\hline $\mathrm{FEV}_{1} / \mathrm{FVC}$ & $0.63 \pm 0.004$ & $0.81 \pm 0.001^{\#}$ & $0.62 \pm 0.005$ & $0.80 \pm 0.001$ \\
\hline \multicolumn{5}{|l|}{ Pre-BD/post-BD change } \\
\hline Absolute FEV1 change $\mathrm{mL}$ & $100.3 \pm 10.6$ & $77.6 \pm 3.1^{\star \star}$ & $119.8 \pm 9.7$ & $93.1 \pm 4.7$ \\
\hline Acute BD reversibility & $113(32.9)^{\star \star}$ & $223(8.0)^{\star}$ & $92(23.9)$ & $104(6.2)$ \\
\hline
\end{tabular}

Data are presented as $n$, mean \pm SE and $n(\%)$. Statistical significance for differences (female versus male) were calculated using the Wald test, adjusted for survey design. BD: bronchodilator; FEV1: forced expiratory volume in $1 \mathrm{~s} ; \%$ pred: \% predicted; FVC: forced vital capacity. *: $p<0.05 ; * \star: p<0.01 ; * \star *: p<0.001 ;{ }^{*}: p<0.0001$. 


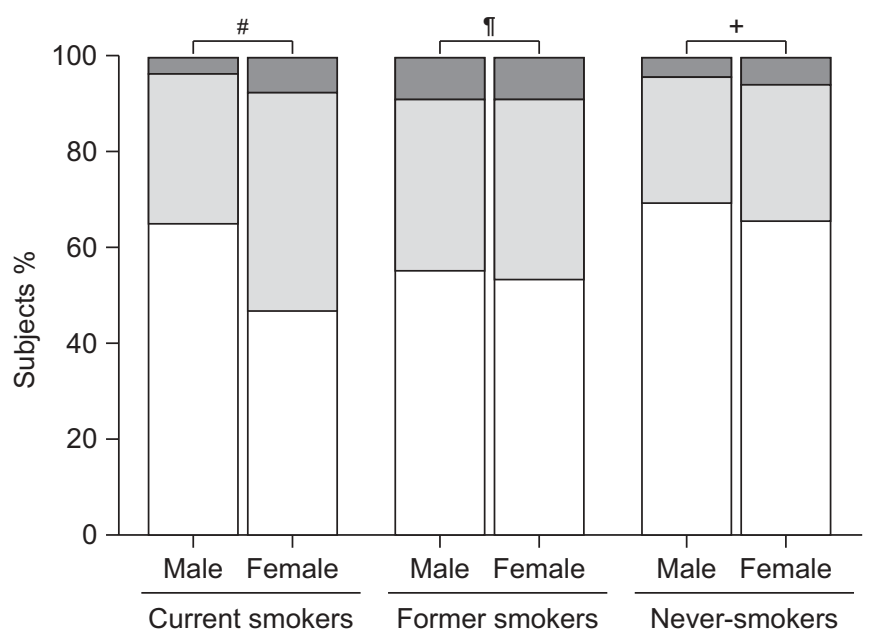

FIGURE 4. Chronic obstructive pulmonary disease severity (Global Initiative for Obstructive Lung Diseases (GOLD) stages) and smoking exposure (pack-yrs) by sex and smoking status. Statistical tests used were as follows. GOLD stage: MannWhitney test and ordered logistic regression (adjusted for survey design); p-values reflect Mann-Whitney test. Mean pack-yrs: Wald test (adjusted for survey design).

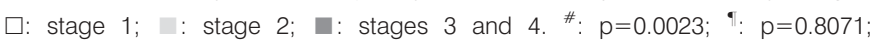
: $p=0.5588$. The mean smoking exposure in current smokers was 28.3 and 25.5 pack-yrs $(p=0.3539)$ in males and females, respectively. In former smokers, mean smoking exposure was 34.9 and 17.5 pack-yrs $(p<0.0001)$ in males and females, respectively.

independently of having COPD. After adjustment for other factors, female sex was important in explaining dyspnoea and SF-12 physical score in the entire study population. Indeed, the sex effect on dyspnoea was comparable to that of other respiratory symptoms characteristic of COPD (cough, wheeze and phlegm). These findings are consistent with those reported in general populations $[23,24]$ and in selected COPD subjects [13-16]. However, COPD seems to have a larger impact on males than females, as measured by the magnitude of differences in perception of health, symptoms and physical performance.
Interactions between airway behaviour and sociocultural determinants are complex [25], and could partially explain some of the sex differences of perception and report of respiratory symptoms. For instance, females reported more shortness of breath and less exercise capacity, whereas sputum production (associated with sex differences in cough reflex sensitivity) was more widely reported in males. At least one population-based study found that, for the same level of FEV1, the rate of dyspnoea was higher in females than in males [26], which is consistent with our findings. The reasons for these differences are not well understood, but it has been suggested that the perception of breathlessness in females is related to hormonal effects on airways [25]. Psychological factors have also been associated with reporting respiratory symptoms. Depressive and anxiety disorders in the general population are more prevalent in females, as well as psychiatric disorders in females with COPD [13]. Unfortunately, measurements for assessing anxiety and depression were not included in the PLATINO study; therefore, their influence could not be evaluated. This could be an important aim for future research.

Comorbidity is another factor that may help explain sex differences in dyspnoea and physical activity. Although comorbidity is increased in COPD patients, its prevalence varies widely among studies [27, 28]. Data from a USA national COPD sample showed that the prevalence of comorbid conditions was similar among females and males except for depression, osteoporosis and cardiovascular disease [29]. Other studies have reported more comorbidity in males with COPD [16]. In the present study, multivariate analysis showed that a higher comorbidity score was independently associated with the presence of dyspnoea and a lower SF-12 physical score in the entire population. We also found a higher comorbidity score in females even without COPD, which could contribute to observed sex differences in dyspnoea. It is possible that older age could partly explain comorbidity in females without COPD, but not in subjects with COPD. Another possible explanation for the higher comorbidity in females could be the limited number of self-reported comorbid conditions assessed in PLATINO (heart disease, hypertension,

TABLE 4 Multivariate logistic regression model explaining dyspnoea in the entire study population*

\begin{tabular}{llr} 
Variable & OR (95\% Cl) & p-value \\
\hline Female sex & & \\
Pre-BD FEV 1 \% pred & $1.60(1.40-1.84)$ & $<0.001$ \\
Comorbidity score per additional comorbid condition & $0.99(0.99-0.99)$ & $<0.001$ \\
Age per year & $1.21(1.13-1.30)$ & $<0.001$ \\
BMI per 1-kg m $^{-2}$ change & $0.99(0.99-1.00)$ & 0.009 \\
White race & $1.06(1.04-1.07)$ & $<0.001$ \\
Education per year & $0.79(0.69-0.90)$ & $<0.001$ \\
SF-12 physical score & $0.97(0.95-0.99)$ & $<0.001$ \\
SF-12 mental score & $0.93(0.92-0.94)$ & $<0.001$ \\
Wheeze & $0.96(0.96-0.97)$ & $<0.001$ \\
Phlegm & $1.64(1.41-1.91)$ & $<0.001$ \\
Cough & $1.55(1.30-1.84)$ & $1.55(1.31-1.84)$ \\
\hline
\end{tabular}

BD: bronchodilator. FEV1: forced expiratory volume in $1 \mathrm{~s}$; \% pred: \% predicted; BMI: body mass index; SF-12: Short Form 12. ${ }^{\#}: \mathrm{n}=5,220$. 


\begin{tabular}{|c|c|c|}
\hline Variable & Coefficient $(95 \% \mathrm{Cl})$ & p-value \\
\hline Pre-BD FEV $1 \%$ pred & $0.01(0.00-0.02)$ & 0.063 \\
\hline Dyspnoea & $-3.51(-3.96--3.07)$ & $<0.001$ \\
\hline Phlegm & $-1.61(-2.22--1.01)$ & $<0.001$ \\
\hline Cough & $-0.90(-1.55--0.25)$ & 0.007 \\
\hline Comorbidity score per additional comorbid condition & $-1.41(-1.64--1.18)$ & $<0.001$ \\
\hline Age per year & $-0.06(-0.09--0.04)$ & $<0.001$ \\
\hline White race & $0.54(0.14-0.94)$ & 0.008 \\
\hline Education per year & $0.14(0.10-0.19)$ & $<0.001$ \\
\hline Employed within past year & $0.93(0.44-1.41)$ & $<0.001$ \\
\hline
\end{tabular}

Model $r^{2}=0.2172$. BD: bronchodilator; FEV1: forced expiratory volume in $1 \mathrm{~s} ; \%$ pred: \% predicted. ${ }^{*}: n=5,220$.

stroke, diabetes, ulcer and asthma). Females also had higher BMI, another factor associated with dyspnoea.

Some studies have reported higher vulnerability in females to the deleterious effects of cigarette smoke [30]. In the current study, females with COPD had lower pre-BD FVC and a higher FEV1/FVC ratio, as well as higher FVC responsiveness compared with males. Although the overall distribution of COPD severity was similar between sexes, females with COPD who were current smokers had more severe COPD, despite similar cigarette exposure. Complicating matters even more, former smokers had no sex differences in severity distribution despite significant differences in smoking exposure histories. These data suggest a more complex relationship between sex and smoking susceptibility.

Female sex has also been associated with airway hyperresponsiveness [31]. This could be attributable to their smaller lung volumes and to hormonal differences [32]. There is an apparent discrepancy regarding acute bronchodilator reversibility by sex. Data from the National Emphysema Treatment Trial indicated that males were more likely to demonstrate reversibility of airway obstruction compared to females [14]. However, results from the Lung Health Study in patients with milder disease did not suggest sex differences in acute bronchodilator responsiveness [33]. We found that acute bronchodilator response was more common in females than in males with and without COPD, which is consistent with studies reporting higher airway hyperresponsiveness in females. Some studies have reported that hyperresponsiveness is associated with obesity in females [34]: the higher BMI associated with female sex in PLATINO [35] could also be a factor related to acute bronchodilator response.

Finally, there are limitations in this study that have been discussed previously $[2,19]$. First, our definition of COPD was based on post-BD FEV1/FVC $<0.70$ at a single examination. Although this is the most widely accepted definition for COPD, it represents a simplified case definition for epidemiological purposes and not a definitive clinical diagnosis. This "fixed ratio" definition has shown some sex bias compared with the LLN definition, but our sensitivity analysis using the latter definition showed no important effects on the findings presented here. We determined acute responsiveness to bronchodilator and not airway hyperresponsiveness (using a methacholine challenge), as the latter was not practical in a house-to-house, population-based survey. We also recognise the MRC scale has limitations as an instrument to measure dyspnoea severity; however, this scale is the most widely accepted measure for quantifying dyspnoea in clinical practice.

In summary, this study indicates that there are important sex differences in the impact of COPD. Independent of COPD status, females report more dyspnoea and physical limitation, and worse general health status than males. Currently smoking females with COPD have more severe obstruction than male smokers, despite similar exposure to cigarettes. In this context, COPD impact can be better characterised in males through changes in respiratory symptoms, health perception and physical performance, and in females through impaired lung volumes and airway reversibility.

\section{SUPPORT STATEMENT}

This study was supported by Boehringer Ingelheim GmbH (Ingelheim, Germany).

\section{STATEMENT OF INTEREST}

A statement of interest for this study can be found at www.erj. ersjournals.com/site/misc/statements.xhtml

\section{ACKNOWLEDGEMENTS}

We would like to acknowledge the Asociación Latinoamericana de Tórax (ALAT) for its support for the PLATINO study. We would also like to acknowledge Boehringer Ingelheim $\mathrm{GmbH}$ (Ingelheim, Germany) for funding the study, and anonymous reviewers for their helpful and constructive comments. The members of the Advisory Committee were S. Buist (Oregon Health \& Science University, Portland, OR, USA) and W. Vollmer (Kaiser Permanente Center for Health Research, Portland, OR, USA). The members of the Executive Committee were C. Torres (Research and Education Department, Fundacion Neumologica Colombiana and La Sabana, El Rosario and Javeriana Universities, Bogota, Colombia), J. Luna (Universidad de San Carlos de Guatemala, Guatemala City, Guatemala) and C. Lisboa 
(Department of Respiratory Diseases, Pontificia Universidad Católica de Chile, Santiago, Chile). The members of the PLATINO team were M. Márquez (Universidad de la República, Montevideo, Uruguay), P. Hallal (Programa de Pós-Graduação em Epidemiologia, Universidade Federal de Pelotas, Pelotas, Brazil), M. Blanco (Universidad de la República, Montevideo, Uruguay), F. Rosa (Faculdade de Tecnologiae Ciências (FTC), Universidade Catolica do Salvador, Universidade Estadual da Bahia, Salvador, Bahia, Brazil) and A. Camelier (Respiratory Division, FTC, Universidade Catolica do Salvador, Universidade Estadual da Bahia, Salvador, Bahia, Brazil).

\section{REFERENCES}

1 Rabe KF, Hurd S, Anzueto A, et al. Global Initiative for Chronic Obstructive Lung Disease Global strategy for the diagnosis, management, and prevention of chronic obstructive pulmonary disease: GOLD executive summary. Am J Respir Crit Care Med 2007; 176: 532-555.

2 Menezes AM, Perez-Padilla R, Jardim JR, et al. Chronic obstructive pulmonary disease in five Latin American cities (the PLATINO study): a prevalence study. Lancet 2005; 366: 1875-1881.

3 Halbert RJ, Natoli JL, Gano A, et al. Global burden of COPD: systematic review and meta-analysis. Eur Respir J 2006; 28: 523-532.

4 Zhong N, Wang C, Yao W, et al. Prevalence of chronic obstructive pulmonary disease in China: a large population-based survey. Am J Respir Crit Care Med 2007; 176: 753-760.

5 Buist AS, McBurnie MA, Vollmer WM, et al. International variation in the prevalence of COPD (the BOLD Study): a population-based prevalence study. Lancet 2007; 370: 741-750.

6 Mannino DM, Braman S. The epidemiology and economics of chronic obstructive pulmonary disease. Proc Am Thorac Soc 2007; 4: 502-506.

7 Chen Y, Horne SL, Dustman JA. Increased susceptibility to lung dysfunction in female smokers. Am Rev Respir Dis 1991; 143 $1224-1230$.

8 Langhammer A, Johnsen R, Holmen J, et al. Cigarette smoking gives more respiratory symptoms among women than among men. The Nord-Trondelag Health Study (HUNT). J Epidemiol Community Health 2000; 54: 917-922.

9 Langhammer A, Johnsen R, Gulsvik A, et al. Sex differences in lung vulnerability to tobacco smoking. Eur Respir J 2003; 21: 1017-1023.

10 Machado MC, Krishnan JA, Buist SA, et al. Sex differences in survival of oxygen-dependent patients with chronic obstructive pulmonary disease. Am J Respir Crit Care Med 2006; 174: 524-529.

11 de Torres JP, Cote C, Lopez MV, et al. Sex differences in mortality in patients with COPD. Eur Respir J 2009; 33: 528-535.

12 Kohansal R, Martinez-Camblor P, Agustí A, et al. The natural history of chronic airflow obstruction revisited: an analysis of the Framingham offspring cohort. Am J Respir Crit Care Med 2009; 180: 3-10.

13 Laurin C, Lavoie KL, Bacon SL, et al. Sex differences in the prevalence of psychiatric disorders and psychological distress in patients with COPD. Chest 2007; 132: 148-155.

14 Martinez FJ, Curtis JL, Sciurba F, et al. Sex differences in severe pulmonary emphysema. Am J Respir Crit Care Med 2007; 176: 243-252.

15 Varkey AB. Chronic obstructive pulmonary disease in women: exploring gender differences. Curr Opin Pulm Med 2004; 10: 98-103.

16 de Torres JP, Casanova C, Hernández C, et al. Gender and COPD in patients attending a pulmonary clinic. Chest 2005; 128: 2012-2016.
17 Tashkin DP, Altose MD, Bleecker ER, et al. The Lung Health Study: airway responsiveness to inhaled methacholine in smokers with mild to moderate airflow limitation. The Lung Health Study Research Group. Am Rev Respir Dis 1992; 145: 301-310.

18 de Torres JP, Casanova C, Hernández C, et al. Gender associated differences in determinants of quality of life in patients with COPD: a case series study. Health Qual Life Outcomes 2006; 4: 72.

19 Menezes AM, Victora CG, Perez-Padilla R, et al. The PLATINO project: methodology of a multicenter prevalence survey of chronicobstructive pulmonary disease in major Latin American cities. BMC Med Res Methodol 2004; 4: 15.

20 American Thoracic Society. Standardization of spirometry, 1994 update. Am J Respir Crit Care Med 1995; 152: 1107-1136.

21 Montes de Oca M, Talamo C, Halbert R, et al. Health status perception and airflow obstruction in five Latin American cities: The PLATINO study. Respir Med 2009; 103: 1376-1382.

22 de Oca MM, Tálamo C, Halbert RJ, et al. Frequency of self-reported COPD exacerbation and airflow obstruction in five Latin American cities The Proyecto Latinoamericano de Investigación en Obstrucción Pulmonar (PLATINO) Study. Chest 2009; 136: $71-78$

23 Summary Health Statistics for U.S. Adults: National Health Interview Survey, 2007 Series 10, Number 240. www.cdc.gov/ nchs/nhis.htm Date last accessed: May 2009. Date last updated: July 26, 2010.

24 National Health Interview Surveys (HIS). www.ec.europa.eu/ health Date last accessed: 2007. Date last updated: August 4, 2010.

25 Becklake MR, Kauffmann F. Gender differences in airway behaviour over the human life span. Thorax 1999; 54: 1119-1138.

26 Pollution atmosphérique et affections respiratoires chroniques ou à répétition. I. Méthodes et matériel. [Air polltuion and chronic respiratory disease. I. Methods and material.] Bull Eur Physiopathol Respir 1982; 18: 87-99.

27 Soriano JB, Visick GT, Muellerova H, et al. Patterns of comorbidities in newly diagnosed COPD and asthma in primary care. Chest 2005; 128: 2099-2107.

28 Sin DD, Anthonisen NR, Soriano JB, et al. Mortality in COPD: role of comorbidities. Eur Respir J 2006; 28: 1245-1257.

29 Barr RG, Celli BR, Mannino DM, et al. Comorbidities, patient knowledge, and disease management in a national sample of patients with COPD. Am J Med 2009; 122: 348-355.

$30 \mathrm{Xu} \mathrm{X,} \mathrm{Li} \mathrm{B,} \mathrm{Wang} \mathrm{L.} \mathrm{Gender} \mathrm{difference} \mathrm{in} \mathrm{smoking} \mathrm{effects} \mathrm{on} \mathrm{adult}$ pulmonary function. Eur Respir J 1994; 7: 477-483.

31 Kanner R, Connett J, Altose M, et al. Gender difference in airway hyperresponsiveness in smokers with mild COPD. The Lung Health Study. Am J Respir Crit Care Med 1994; 150: 956-961.

32 Scichilone N, Messina M, Battaglia S, et al. Airway hyperresponsiveness in the elderly: prevalence and clinical implications. Eur Respir J 2005; 25: 364-375.

33 Anthonisen NR, Lindgren PG, Tashkin DP, et al. Bronchodilator response in the lung health study over 11 yrs. Eur Respir J 2005; 26: $45-51$.

34 Sood A, Dawson BK, Eid W, et al. Obesity is associated with bronchial hyper-responsiveness in women. I Asthma 2005; 42 847-852.

35 Montes de Oca M, Talamo C, Perez-Padilla R, et al. Chronic obstructive pulmonary disease and body mass index in five Latin American cities: The PLATINO study. Respir Med 2008; 102: 642-650. 